\title{
Medidas e proporções orofaciais de crianças respiradoras orais
}

\author{
Débora Martins Cattoni ${ }^{1}$
}

Cattoni DM. Medidas e proporções orofaciais de crianças respiradoras orais [tese]. São Paulo: Universidade de São Paulo; 2006.

Introdução: A avaliação antroposcópica da morfologia orofacial e a mensuração das estruturas faciais são importantes aspectos do exame fonoaudiológico, contribuindo para a determinação do diagnóstico, do planejamento terapêutico e do prognóstico dos indivíduos com respiração oral. Objetivos: Os objetivos da tese foram: 1 . descrever as características posturais e morfológicas dos órgãos fonoarticulatórios de crianças respiradoras orais, segundo a idade; 2. descrever as medidas e proporções orofaciais de crianças respiradoras orais, segundo a idade e; 3 . comparar as medidas e proporções orofaciais de crianças respiradoras orais com as medidas e proporções orofaciais de crianças sem queixas fonoaudiológicas, segundo a idade. Métodos: A tese encontra-se dividida em três estudos, a saber: Estudo I - Características posturais e morfológicas dos órgãos fonoarticulatórios de crianças respiradoras orais: enfoque antroposcópico; Estudo II - Medidas e proporções orofaciais de crianças respiradoras orais; e Estudo III - Comparação entre medidas e proporções orofaciais de crianças respiradoras orais e de crianças sem queixas fonoaudiológicas. Participaram dos estudos 100 crianças, de ambos os sexos, com idades entre 7 anos e 11 anos e 11 meses, leucodermas, em dentição mista, com diagnóstico de respiração oral. No Estudo III, o grupo controle foi composto de 254 crianças, de ambos os sexos, na faixa etária entre 7 anos e 11 anos e 11 meses, leucodermas, em dentição mista e sem queixas fonoaudiológicas. As características posturais e morfológicas dos órgãos fonoarticulatórios das crianças respiradoras orais pesquisadas no Estudo I foram posição habitual de lábios e de língua, possibilidade de vedamento labial, hiperfunção do músculo mentual durante a oclusão labial, mordida e morfologia do lábio inferior, das bochechas e do palato duro, por meio da antroposcopia. Nos Estudos II e III, as crianças foram submetidas à avaliação antropométrica, sendo que as medidas orofaciais obtidas foram lábio superior, lábio inferior, filtro, terço superior da face, terço médio da face, terço inferior da face, lados da face e distância interincisiva máxima. As proporções orofaciais calculadas foram entre o lábio superior e o lábio inferior, entre o terço superior da face e o terço médio da face e entre o terço médio da face e o terço inferior da face. $\mathrm{O}$ instrumento utilizado foi o paquímetro eletrônico digital marca Starrett Série 727. Resultados: Os resultados do Estudo I indicaram que os aspectos mais comuns na amostra foram posição habitual de lábios entreaberta, posição habitual de língua no assoalho oral, possibilidade de vedamento labial, hiperfunção do músculo mentual durante a oclusão labial, mordida alterada, lábio inferior com eversão, simetria de bochechas e palato duro alterado. No Estudo II, foi verificado que não houve diferença estatisticamente entre a maioria das médias das medidas e proporções orofaciais de crianças respiradoras orais, segundo a idade. Os resultados do Estudo III mostraram que para o lábio superior, lábio inferior, terço inferior da face, lados da face, proporção entre o lábio superior e o lábio inferior e proporção entre o terço médio da face e o terço inferior da face houve diferença estatística entre as duas populações estudadas. Conclusões: A antropometria mostra-se útil na avaliação fonoaudiológica, complementando o julgamento visual com medidas quantitativas. Ao analisar os três estudos, podese concluir que as alterações antroposcópicas parecem ser mais evidentes nos respiradores orais do que as alterações antropométricas.
(1) Doutora em Ciências pela Faculdade de Medicina da Universidade de São Paulo - USP - São Paulo (SP), Brasil; Colaboradora do Ambulatório de Atenção Primária em Fonoaudiologia da Universidade de São Paulo - USP São Paulo (SP), Brasil.

Tese apresentada à Faculdade de Medicina da Universidade de São Paulo para obtenção do título de Doutor, sob a orientação da Profa. Dra. Fernanda Dreux Miranda Fernandes.

Endereço para correspondência: Débora Martins Cattoni. R. Barão da Passagem, 1330/91C, São Paulo - SP, CEP 05087-000. E-mail: dmcattoni@uol.com.br 